\title{
Fronteras y periferias en la historia del capitalismo: el caso de América Latina'
}

\author{
Margarita Serje de la Ossa²
}

\begin{abstract}
RESUMEN
Las regiones de frontera y los confines han sido usualmente estudiados en el contexto de las historias y de los procesos de formación de las naciones y sus "comunidades imaginadas". Sin embargo, la historia de los márgenes y periferias, como los entendemos en el mundo contemporáneo, nace con la historia del capitalismo. En este trabajo se pretende situarlos en este contexto, mostrando cómo una de las estrategias necesarias para la expansión del capital, ha sido la transformación (mediante una serie de prácticas discursivas y materiales) de una serie de regiones en "tierras de nadie", en espacios donde se impone un régimen de excepción que define los términos de su desarrollo y su articulación a la economía global. Con este objetivo, se explora el caso de las regiones categorizadas como periféricas en América Latina. Con el fin de desnaturalizar la idea de márgenes y periferias, se muestra la forma en que las nociones que las constituyen (como regiones salvajes y despobladas que ocultan enormes riquezas), oculta la racionalidad y la lógica de las intervenciones mediante las cuales se implementan las formas particulares, y en muchos casos brutales, que adopta aquí el capitalismo.
\end{abstract}

Palabras clave: Fronteras, periferias, estrategias espaciales, historia del capitalismo.

\begin{abstract}
Frontier lands and remote territories have usually been studied in the context of national histories, as part of the formation of nations and their "imagined communities". However, the history of margins and peripheries, as we understand them today, is more closely related to the history of capitalism. In this paper, my aim is to situate them in this context, in order to shed light to the fact that one of the most important spatial strategies for the expansion of capitalism has been the transformation (through a series of discursive and material practices) of many historical regions in the planet into "no man's lands": into spaces subjected to a regime of exception. This regime defines both the model of development they will have to adopt, and the manner in which they are to be articulated to the world economy. This paper explores the regions categorised as peripheral in Latin America from this perspective. In order to denaturalize them as margins and peripheries, the notions that constitute them (eg. as wild and deserted lands teeming with riches) will be explored, exposing their function in obscuring the logic and the brutal rationality of capitalist interventions.
\end{abstract}

Key words: Frontiers, peripheries, spatial strategies, history of capitalism. 
Las "fronteras"3 y las regiones periféricas han sido usualmente estudiadas en el contexto de las historias y de los procesos de formación de los Estados nacionales y sus "comunidades imaginadas" (Anderson, 1991); en tanto que "márgenes del Estado" (Das y Poole, 2004) o como parte de lo que en otro trabajo Serje (2006) he llamado "el revés de la nación"4. Sin embargo, la historia de las "fronteras" y las periferias nace mucho antes de las naciones: nace con la historia del capitalismo. De hecho, en los espacios de frontera se hace evidente que en medio de las transformaciones por las que ha atravesado en las últimas décadas el concepto y la configuración del Estado-nación, el geo-cuerpo de las naciones (Winichakul, 1997) se ha visto transformado espacial y simbólicamente precisamente por la enorme diversidad de fronteras que lo cruzan y la complejidad de los procesos que las constituyen. La multiplicidad y proliferación de estos procesos evidencia que las fronteras se han vuelto cruciales y más que a fenómenos locales o nacionales responden a fenómenos globales, muchos de ellos inherentes a las dinámicas del capital (Mezzadra \& Neilson, 2013).

Los conceptos mismos de "frontera" y de periferia, como los entendemos hoy -es decir, como sinónimos que denotan un conjunto de espacios "otros", vacíos y dispuestos para ser tomados, conquistados e intervenidos, que se representan como lugares remotos, en disputa, desarticulados y atrasados, disponibles para ser penetrados y explotados- adquieren este sentido en la historia del mundo capitalista moderno. Contrastan, por lo demás, con otras formas de entender las fronteras y confines en tradiciones como las de las sociedades bosquesinas de la Amazonia (Gasché y Echeverri, 2004) o la del antiguo reino de Siam, hoy Tailandia (Winichakul, 1997) por mencionar solo un par de ejemplos 5 .

Los conceptos de "frontera" y periferia son sinónimos en tanto que la idea de frontera interna, que en ciertos casos se superpone a la frontera político administrativa, hace referencia simultáneamente a una cantidad de sentidos que quedan ocultos y naturalizados tras la noción de frontera internacional: denota fronteras étnicas, geográficas, climáticas y culturales. Pero sobre todo, estas dos nociones demarcan la frontera de la civilización, es decir del Orden Moderno6, poniendo en evidencia los alcances de su infraestructura y de su logística, de sus conexiones económicas y de sus formas de control: la frontera interna es a la vez frontera agrícola, frontera militar y frontera de la "presencia" del Estado. La frontera interna se piensa y se conceptualiza, por ello, como periferia.

En este trabajo me interesa, por ello, situar las "fronteras" y las periferias en este contexto: en el de la historia del capitalismo. Voy a mostrar cómo, una de las estrategias centrales para la expansión del capital es la transformación de ciertas regiones históricas en fronteras y periferias donde se hacen posibles y tolerables una serie de intervenciones discursivas y materiales que definen los términos de su articulación y desarrollo. Además, el situar en la historia del capitalismo las regiones categorizadas como periféricas -entre las cuales en una cierta escala se sitúa Amé-

\footnotetext{
En este trabajo, voy a usar el concepto de "frontera" entre comillas para referirme a la noción de frontera interna, que tiene un significado particular, correspondiente a frontier que en inglés se diferencia de border que se refiere a la frontera como límite político administrativo.

4 Casi me atrevería a afirmar que la mayoría de los trabajos sobre periferias márgenes, fronteras, tierras de nadie, por lo menos en el caso latinoamericano, se han propuesto teniendo la nación y los limites nacionales como referente, ver adelante la nota 9.

5 Donde la frontera más que denotar límite de soberanía, es un espacio compartido de soberanías múltiples, más que ser pensado como una línea se piensa como un espacio abierto y poroso

6 Por moderno se hace referencia en este trabajo al conjunto de procesos relacionados con la puesta en marcha, la consolidación y expansión del sistema mundial capitalista moderno
} 
rica Latina en general- permite dos cosas fundamentales: primero, desnaturalizar o si se quiere des-fetichizar las periferias y, en segundo lugar, permite pensar su función social.

Por lo demás, no sobra destacar la importancia que tiene hoy estudiar el capitalismo, no únicamente como proyecto económico, sino como formación social y cultural, cuya historia comenzó a finales de la edad media cuando nace la idea de riqueza entendida como capital que nos parece hoy completamente natural, dando inicio a una era que ha transformado radicalmente al planeta y a los seres humanos.

Se trata de un proyecto que es fundamental conocer no solo en términos de su dimensión técnico-económica, sino en términos de su dimensión social y cultural, pues no solo ha naturalizado una idea de riqueza (que contrasta, por lo demás con ideas mucho más interesantes de riqueza que han sido desarrolladas por otras sociedades), ha naturalizado también una forma de ver la naturaleza y la naturaleza de las cosas, que debemos repensar. Sobre todo hoy, cuando hay un reconocimiento generalizado de que a pesar de sus brillantes logros artísticos, tecnológicos y científicos, el capitalismo presenta brutales fracasos en el campo de lo social y lo ecológico. Se trata de un proyecto político y económico que ha producido violencia, injusticia y formas de exclusión y desigualdad social extremas y cuya voracidad de recursos tiene hoy en jaque el clima y la diversidad de la vida en el planeta, al tiempo en que -y esto es quizás lo más grave- sus costos se consideran moralmente aceptables.

\section{Las estrategias espacio-temporales del capitalismo}

El capitalismo ha producido a lo largo de su historia formas específicas de territorialidad y de espacialidad (Lefebvre, 1994; Harvey, 2004, 2006) por medio de un conjunto de prácticas deliberadas que han venido siendo puestas en marcha de forma sistemática, para producir los efectos instrumentales que hacen posible las condiciones de anexión de ciertos territorios y lugares a los circuitos del capital. Estas prácticas aparecen entonces, como propiedades emergentes del proceso de desarrollo -múltiple e interactivo- del capital.

Así, este conjunto de prácticas son inseparables las unas de las otras y han sido centrales para la producción de un espacio abstracto y global para la expansión y la acumulación del capital, que parte de la idea de que el planeta es un espacio en blanco disponible para ser apropiado y explotado, independientemente de la vida de sus habitantes y sus paisajes. Han tenido la función de configurar la geografía que requiere la anexión de nuevos recursos y paisajes al capital. Podemos considerarlas como estrategias espaciales pues son constitutivas de la espacialidad del sistema mundial moderno ${ }^{7}$, del espacio global del capital. Producen una realidad espacial, al tiempo en que las condiciones de su producción se ven opacadas.

Desde una perspectiva histórica, es posible visualizar estas estrategias espaciales en la larga duración. Entre ellas, se puede destacar primero el surgimiento de la idea de la propiedad privada alrededor del siglo XIV, que implicó la apropiación, privatización y desalojo de los comunes

Para caracterizarlas me baso en varios trabajos, en particular los de Marx (1992), Rama (1984), Santos (1975), Harvey (2004, 2006), Lefebvre (1991), y Deleuze y Guattari (1980). 
primero en Europa y luego en América, África y Asia. Segundo, el ordenamiento del espacio con base en los principios del espacio utópico (por oposición al espacio histórico o espacio tópico) que trajo consigo la organización del mundo a partir de líneas divisorias físicas y simbólicas y el consecuente establecimiento de los territorios y las naciones como espacios discretos; tercero, la concentración de las actividades financieras y de consumo en núcleos urbanos, lo que ha implicado la hiper-urbanización del planeta; y cuarto, el desplazamiento y el reasentamiento de cantidades cada vez mayores de población para responder a las necesidades del capital.

Y, sin duda, otra de las estrategias centrales ha sido la de fundar la organización espacial de la producción y del trabajo (Harvey, 2004 y 2006; Mezzadra \& Neilson, 2013; Anievas \& Nisancioglu, 2015), en la supuesta existencia de "periferias". Es decir, en la producción de espacios externos a los centros de acumulación del capital y el consumo que se entienden como "fronteras" económicas, geográficas y culturales abiertas y disponibles para la extracción de riqueza. Esta forma de producción del espacio, que es condición de posibilidad del proyecto colonial y del imperialismo, ha sido objeto de diversos debates desde el punto de vista de su función económica y política (Galeano, 1971; Luxemburg, 2003; Harvey, 2004). En este artículo me interesa centrarme en la oposición centro/periferia como una práctica discursiva, para discutir sus efectos específicos, tanto simbólicos como materiales, en la medida en que esta forma de producción del espacio configura un modelo geográfico -en el que un conjunto de regiones que aparecen ausentes y apartadas, se articulan al capitalismo en condiciones particulares que implican el desplazamiento (físico y/o simbólico) de sus habitantes y el uso irresponsable y cortoplacista de sus paisajes y recursos- y un modelo histórico, que sitúa las formaciones sociales pre-existentes en estas regiones en la ruta crítica del desarrollo y de la civilización como espacios y poblaciones "exteriores" primitivos y atrasados (Galeano, 1971; Lévi-Strauss, 1973; Esteva, 1992; Anievas \& Nisancioglu, 2015).

\section{La oposición centro-periferia}

La historia del capitalismo se ha enfocado, normalmente, en sus lugares y espacios centrales. El papel central que tuvieron muchas -sino todas- las regiones "salvajes" y "apartadas" del planeta en su desarrollo ha tenido un papel periférico. Quizás por ello, en términos generales, cuando en el sentido común se habla de capital se tiende a pensar en los centros financieros y tecnológicos o en los distritos de consumo, y no en los tugurios e invasiones que son su correlato; se piensa en ciudades como Londres o Nueva York y poco en Manaos (Amazonas) o Puerto Príncipe (Haití), que fueron ciudades globales en el desarrollo del sistema capitalista mundial y florecieron como sus centros extractivos, como nodos de los ejes de circulación de mercancías (en este caso el caucho y el azúcar) y como centros de concentración de miles de esclavos indios y africanos. La relación entre estos nodos espaciales se ha conceptualizado por medio de la oposición centro-periferia.

A pesar de sus obvios efectos concretos (expresada, por ejemplo, en la distribución global del PIB, del ingreso per cápita, o del acceso a servicios), es necesario comenzar por problematizar las implicaciones que tiene el caracterizar la organización geográfica de la producción del capital por medio de la oposición centro-periferia. Si para hacerlo se hace referencia a las múltiples formas en que la producción se orienta al capital, y los procesos que resultan de las luchas y encuentros del capital con las distintas formas de vida y de producción con las que interactúa (Anievas \& Nisancioglu, 2015), vemos que esta oposición no es entonces únicamente una conceptualización 
descriptiva y analítica, sino una forma concreta de intervención que tiene efectos tanto materiales como simbólicos.

Para explorar su función social es necesario comenzar por señalar que desde un punto de vista teórico, se trata de una falsa oposición. Efectivamente, los espacios que consideramos como centros y periferias no constituyen realidades opuestas, como si cada una hiciera parte de una lógica y de una historia distinta a la de la otra (por un lado, un mundo "desarrollado" y, por otro, uno "atrasado" y "subdesarrollado"), sino que ambas hacen parte de una misma racionalidad. Así, Paris con sus domos dorados y sus anchos bulevares donde se exhiben maravillosas y exóticas mercancías, hace parte del mismo proceso político, económico, militar y cultural del que surge la economía esclavista de plantaciones en Santo Domingo, hoy Haití. Son parte de un mismo proceso: el del desarrollo del capital. El "desarrollo" de Paris y el "atraso" de Haití, son dos caras de una misma moneda ${ }^{8}$.

En segundo lugar, la historia económica nos ha mostrado que las economías constitutivas de las periferias -que se basan en regímenes extractivos, caracterizados por articular formas extorsivas y muchas veces abiertamente esclavistas de trabajo con la explotación intensiva de recursosno han tenido para nada un papel marginal en el desarrollo del capitalismo. Al contrario, han sido y siguen siendo centrales. Han sido los espacios donde, mediante el establecimiento de formas extremas de trabajo que configuran diversas formas de esclavitud, se produce la "acumulación primitiva del Capital". Así como el comercio de esclavos del Atlántico fue condición de posibilidad del desarrollo de la revolución industrial (Drayton, 2002; Beckert, 2016), la "nueva esclavitud" (es decir la esclavitud contemporánea ligada al endeude y de la ilegalidad del trabajo migrante) es también condición para el sostenimiento de la llamada economía global: es la base de la boyante industria de la moda, o de la economía de las frutas en la Florida y las Carolinas en Estados Unidos, por mencionar solo un par de ejemplos (Bales, 1999).

El tercer aspecto problemático de esta forma de caracterizar la organización espacial de la economía es lo que pudiéramos llamar su carácter fractal. Los objetos fractales en la teoría del caos (cf. Gleick, 2008) son aquellos cuya estructura básica, fragmentada o irregular, se reproduce en todas las escalas. Es decir, que en cualquiera de sus dimensiones, el objeto fractal presenta siempre la misma estructura. Y, efectivamente, la estructura centro-periferia se reproduce en las distintas escalas: a escala global aparecen hoy como el centro los países del llamado Grupo de los 8, con vastas periferias entre las que se encuentran el Sudeste Asiático, el África y enormes regiones de América Latina. Vemos también que esta estructura se reproduce a escala regional, Singapur como centro en el sudeste asiático; Nairobi en el África; México y Sao Paulo en América Latina. Y claramente, a escala nacional: en Colombia, la región andina mantiene una relación de centro con la Orinoquia y la Amazonia que se consideran periferias. En Perú, Chile y Bolivia por el contrario, es la sierra la que tiene un papel periférico frente a la llamada "media luna" en el piedemonte amazónico, en el caso boliviano; y frente a la región costera en el caso peruano y el chileno.

No sobra recordar que una de las contribuciones más importantes de la "Teoría de la dependencia" (Cardoso y Faleto, 1969; Amin, 1973; Dos Santos, 1972; y Frank, 1978) fue precisamente poner este hecho en evidencia. 
Y la misma estructura se reproduce en el interior de las regiones y unidades. Así, encontramos "regiones periféricas" en "países centrales" como El Yukón en Canadá, o la que se conoce como la "Francia Profunda". A su vez, las periferias tienen zonas centrales, como la ciudad de Manaos, hoy zona franca en la Amazonia donde se construyó durante el boom del caucho una réplica de la Ópera de Paris.

Puesto que la existencia de periferias es condición de posibilidad del desarrollo de los centros y dado que lo que se desarrolla, más que las regiones particulares, es la "economía-mundo", es decir, el sistema general; los centros y las periferias van migrando aunque manteniendo siempre la misma estructura. Si Paris fue la "capital del siglo XIX", Nueva York fue la del siglo XX, evidenciando el desplazamiento definitivo de Europa del "centro" del orden mundial.

Y sin duda, también las periferias han ido migrando. España, que durante el siglo XV fue el centro de Europa, pasó luego a ser una de sus periferias interiores. La India, que fue la gran periferia del imperio británico, es hoy una de las llamadas "economías emergentes", mientras que la Antártida o el Amazonas que hasta hace unas décadas aparecían como regiones remotas e inalcanzables son ahora periferias extractivas para el petróleo y la minería.

Quisiera señalar aquí que este efecto no es una anomalía que se manifiesta solo en casos aislados. Al contrario, se trata de un efecto sistémico y global. Si se mira la historia del capitalismo desde sus llamadas regiones periféricas, es posible ver como aparece una geografía particular, conformada por una serie de regiones caracterizadas como vastas y agrestes, turbulentas en muchos casos y siempre en disputa por la "maldición de sus recursos". Esta realidad la describen desde las diferentes "periferias" del planeta, Edward Said (1979), palestino, para el caso del "oriente", Valentín Mudimbe (1988) del Congo Belga, para el caso de África como continente, Michel-Rolph Trouillot (1988), haitiano, para el caso de las Antillas, Winichakul Tongchai (1997), para el caso de Tailandia, Ranabir Samaddar (1999) para la región de Bengala, Partha Chatterjee (1994) para el de la India (y esto solo para mencionar algunos ejemplos).

Es desde esta perspectiva que quiero proponer una mirada panorámica de la experiencia latinoamericana, donde en el sentido común se mantienen y se legitiman una serie de nociones -y de relatos- sobre el continente, sus paisajes y sus habitantes que dan orden y sentido al territorio y a sus naciones. Se trata de un conjunto de conceptos y categorías que tienen una sorprendente continuidad histórica y que fundamentan las reflexiones de muchos saberes expertos y campos especializados hasta hoy. Esta arquitectura conceptual se forja en la mirada alucinada de los conquistadores y sus trazos subsisten en el ojo experto de los técnicos y administradores hasta nuestros días.

\section{Periferias en América Latina}

Como lo ha señalado Ángel Rama (1984), la ciudad hispanoamericana no surge orgánicamente de los meandros de la historia y de la geografía de los lugares: fue una ciudad concebida a partir del rigor de la escritura, construida según la pauta inexorable de la letra de la ley-de las Ordenanzas- mediante las cuales se escritura el poder colonial. La ciudad aquí no es meramente un espacio. Es, sobre todo (como lo apunta Subirats, 2005), un artefacto jurídico y teológico configurado 
para responder a la necesidad de administrar la masa indígena desposeída y desarraigada, de movilizarla como fuerza de trabajo esclavo y semiesclavo. La ciudad colonial fue así un dispositivo del control administrativo y eclesiástico. De esta misma forma, para el proyecto urbano-católico colonial, los espacios que quedan por fuera del orden de la ciudad, es decir, las fronteras internas y las periferias, van a ser configurados también de acuerdo con la pauta de la letra y de la ley. Estas regiones y paisajes se configuran como espacios discursivos, que se definen y se caracterizan antes de ser explorados y conocidos. Existen primero en la imaginación y se van a ver reducidos a pura representación (ver Said, 1979; Subirats, 1994; Trouillot, 1988, y Serje, 2006).

Aquí, las tierras y los comunes de los indígenas americanos se caracterizaron como territorios salvajes y tierras de nadie, por medio del establecimiento de una cartografía y una zonificación político-administrativa virtual, que se impuso de manera imaginaria sobre un territorio desconocido. La categorización de la geografía de la resistencia al dominio colonial como lugares peligrosos e inhóspitos, pero plagados de enormes riquezas fue parte del montaje del proyecto urbano-católico, que se emplaza (parafraseando a Rama) precediendo al territorio y se configura como un sistema de enclaves que constituyen la punta de lanza del proyecto de civilización. Este sistema de enclaves ignora la continuidad histórica y geográfica para articular los territorios, no internamente ni de acuerdo a las dinámicas y al tejido social de sus habitantes, sino de acuerdo a los flujos del capital metropolitano.

Se destacan así, a lo ancho del continente y en la larga duración, una serie de regiones (abiertas, fluidas, cambiantes, siempre porosas, siempre en disputa) que, aunque aparecen como "fronteras interiores", casi siempre son espacios multinacionales. Entre estas se cuentan, por ejemplo, el "gran desierto del norte" (México-Estados Unidos), los Llanos de la Orinoquia (Colombia-Venezuela), la península de Yucatán (México-Guatemala), el desierto de Atacama (Perú-Chile), la Puna peruana y boliviana, el "tapón" del Darién y el Chocó-Pacífico (Costa Rica-Panamá-Colombia), el Gran Chaco (Paraguay, Bolivia, Argentina) la Patagonia (Chile-Argentina) y la enorme extensión de la Amazonia sobre la que tienen soberanía nueve Estados, incluido el Francés.

\section{El efecto periferia}

Es curioso que al mirar uno a uno estos casos, rápidamente se llega a la saturación: se llega a un punto en el que cada nuevo caso reitera las mismas imágenes y representaciones prácticamente sin aportar elementos propios y particulares de cada lugar a la descripción. Estas regiones tan disimiles se describen todas, sospechosamente, en los mismos términos: como "desiertos" amenazantes, remotos e inhóspitos. Se conciben como como lugares deshabitados o poco poblados, habitados por grupos salvajes que pueden ser desechados. Aparecen como regiones que prometen riquezas quiméricas que deben ser sometidos a regímenes especiales, como territorios en disputa marcados por la violencia?

\footnotetext{
Existen numerosos trabajos que exploran los tropos mediante los cuales se describen y se piensan estas regiones. Se pueden destacar los de Rajchenberg y Heau-Lambert (2005, 2007); Pérez-Taylor et al. (2007), y Montejano (1987) para el caso del Gran Desierto México-Americano; Caso-Barrera (2002) para Yucatán, Serje (2005) para las fronteras internas en Colombia; Nuñez et al. (2013), y López (2003) para el caso de las "fronteras móviles" del cono sur, así como las historias de la Patagonia de Navarro Floria (1999) y Bandieri (2014); García Jordán (2002), y Santos Guerrero y Barclay (1995), para los "orientes" de Perú y Bolivia, respectivamente.
} 
Es posible identificar también un conjunto específico de líneas de intervención que se implementan mediante regímenes distintos, pero que mantienen una serie constantes: estas fronteras invariablemente se gobiernan desde fuera, ya sea desde gobiernos centrales o desde zonas metropolitanas mediante figuras recurrentes como baldíos nacionales, zonas político administrativas "especiales", concesiones, regiones y territorios "nacionales", etc.

Esta sospechosa recurrencia de imágenes y formas de intervención, pone en evidencia que la oposición centro-periferia no es únicamente una noción teórica que nos permite caracterizar la organización espacial de la producción y la acumulación del capital. Como idea constituye, en sí misma, una estrategia instrumental que produce efectos específicos que son fundamentales y operativos para el desarrollo del capitalismo.

En "La acumulación del capital", Rosa Luxemburg llama la atención a la necesidad que tiene el capitalismo de crear "un entorno de formas de producción no capitalistas" (2003: 348), es decir la necesidad de contar con "una exterioridad que va a ser colonizada de manera metafórica, al tiempo en que la colonización va abriendo, literalmente, nuevos espacios para la penetración del capital en nuevos territorios" (Mezzadra \& Nielson, 2013:75). Se crea así una exterioridad al capitalismo, donde "con el desarrollo avanzado de los países [o espacios] capitalistas y su cada vez más inexorable competencia por adquirir áreas no capitalistas, el imperialismo crece en ilegalidad y violencia, tanto en su agresión contra el mundo no capitalista como en el escalamiento de los conflictos de esta competencia" (Luxemburg, 2003: 427).

La producción de esta exterioridad constitutiva del capital constituye lo que voy a denominar en este trabajo el "efecto periferia". Este se configura mediante un campo semántico que articula un conjunto de nociones que aparecen como naturales y hacen parte del sentido común, que tienen efectos sobre las relaciones sociales y que son factor de violencia de muchos tipos (violencia estructural, simbólica, infraestructural, ecológica, etc.). El caso latinoamericano muestra que se configura así una espacialidad constituida por territorios marginales y fronterizos, que no han estado nunca por fuera del dominio del capital y que, de hecho, hacen parte de la geografía imaginaria y "letrada" en el sentido de Rama (1994), que se consolida con la conquista. Los múltiples mecanismos de acumulación del capital que se han sucedido históricamente en estas regiones, conocidas muchas veces como "capitalismo salvaje", han tenido como condición de posibilidad este "efecto especial" que es tridimensional: se materializa por medio de estados imbricados de opacidad, de emergencia y de excepción.

\section{Opacidad}

El estado de opacidad se produce mediante el conjunto de representaciones que recubre estas regiones y que invisibiliza sus habitantes históricos y sus paisajes sociales, creando una especie de fetichismo geográfico por medio del cual se logra "ocultar mostrando". Detrás de su "magia salvaje" se ocultan los procesos históricos y geográficos que han constituido estas regiones.

Resulta llamativo el hecho de que todas estas regiones sean pensadas como "desiertos" en el sentido de baldíos desocupados; ya sea el "gran norte" mexicano o a la Patagonia cruzada por los ríos y lagos del extremo sur del continente, la Puna peruana y boliviana, llegando incluso a aplicarse este adjetivo a zonas húmedas y selváticas como Yucatán, el Darién, el Chaco o la Amazonía que se describen como vastos "desiertos verdes". 
Como lo señala Ortelli, en la tradición del "occidente medieval la percepción acerca del desierto estuvo siempre formada de realidades materiales y simbólicas que se entrelazaban [...]. En el mundo templado y sin grandes extensiones áridas de la Europa medieval las ideas e imágenes asociadas con el desierto estuvieron representadas en el bosque, un lugar de naturaleza enteramente diferente desde el punto de vista de la geografía física, pero al que se le adjudicaban los rasgos simbólicos y culturales del desierto [...]. La voz desierto refería fundamentalmente, "un lugar despoblado, solo, inhabitado'"(Ortelli, 2011: 19-20). Así, Trejo Barajas (2011: 7-8) señala que el "desierto se asoció, por quienes se asumían como la expresión de la civilización, a tierras lejanas, salvajes, incultas; por lo tanto aunque en ellas habitaran miles de nativos se les consideraba despobladas $[\ldots]^{10 \prime \prime}$.

No hay que olvidar que varias de estas zonas son centrales para sus habitantes históricos, quienes las consideran "ombligos del mundo" como el Petén en Yucatán o la Sierra Nevada de Santa Marta en el norte de Colombia. Este hecho desnaturaliza y pone en evidencia el carácter geopolítico de la noción de baldío, mostrando que el dominio histórico y el poder real de los Estados nacionales sobre estos territorios ha sido imaginario, "desertificando simbólicamente enormes porciones de cada país" (Rajchenberg y Héau, 2007: 192).

Efectivamente, la idea de desierto denota que se piensan como lugares cuyo poblamiento histórico (indígena en la mayoría de los casos pero también por parte de colonos de variadas procedencias) es prescindible, al tiempo en que contribuye a pensarlas como minas sin dueño, disponibles para ser tomadas. Así lo evidencian (parafraseando a López, 2003) los acontecimientos que protagonizan estas regiones, así como su constante ocupación por parte de actores externos de las mejores tierras o las múltiples fiebres del oro, entre otros ejemplos.

Este es el segundo aspecto que quisiera subrayar: el hecho de que se piensan como lugares que prometen (a veces elusivamente) enormes riquezas. Susana López en su trabajo sobre la Patagonia argentina, señala que "hay dos concepciones de la naturaleza que juegan en las miradas de la Patagonia cuando se piensa en qué hacer con ella: como reservorio, para mantenerla en estado puro y hacerla objeto de contemplación -concepción que sigue vigente hoy, como es notorio, desde la perspectiva turística- y como naturaleza productiva, para la explotación económica" (Lopez, 2003:10).

Es interesante también, el hecho de que todas estas representaciones, como lo señalan Rajchenberg y Héau (2007), parece que hubieran sido "escritas en tinta indeleble" pues siguen estando vigentes. En 2015, el ministro del medio ambiente en Colombia afirmó públicamente, refiriéndose a un Parque Nacional en la Amazonia, que allí "no hay vida humana, salvo los indígenas que se considera que todavía están allí, que nunca han salido de allí, pero allá no hay vida humana" (Revista Semana, 12 de septiembre de 2015). Con esta frase, que hubiera podido ser proferida en 1515, reitera el viejo imaginario colonial que ve a los indios como salvajes e incluso como animales, como parte de la naturaleza convirtiendo de un trazo su territorio es un espacio despoblado y libre por lo tanto para ser tomado.

Señala también que "los llamados desiertos están ligados también al concepto de frontera, dado que por lo general han sido territorios donde, desde la perspectiva civilizatoria occidental, se debaten la 'civilización y la barbarie' [...] La conquista de los 'desiertos' permitió ampliar los limites, es decir la frontera del dominio colonial , y aunque se convirtió en una tarea de gran envergadura para las huestes conquistadoras no culmino en tiempos coloniales y continuo en los de formación de las naciones" (Trejo-Barajas, 2011: 8) 
Aunque se ha afirmado que este tipo de regiones se caracterizan por ser vacíos, tanto en el mapa como en la simbolización de la nación, he mostrado aquí por el contrario que están llenas de contenidos que siguen vigentes en el sentido común y que las distorsionan, invisibilizando su historia y su geografía social. Este conjunto de tropos no representa únicamente una curiosidad teórica e interesante, tiene importantes efectos sociales, pues el conjunto de nociones que lo constituyen han sido condición de la anexión de las fronteras salvajes al capital, a la periferia del sistema mundial moderno.

\section{Emergencia}

El estado de emergencia surge de los escenarios permanentes de crisis con los que se caracteriza la vida en las zonas de periferia: las sequías e inundaciones, la pobreza y el hambre, el abandono y la ausencia del Estado, donde la exclusión y la injusticia social y la degradación ecológica, se describen mediante "narrativas de crisis que enfatizan cómo las medidas correctivas funcionan en todas partes excepto [en este tipo de lugares]", como lo pone Fermé (1998: 558) para el caso de África. Esta forma de caracterizar las situaciones que se viven en las "fronteras" y periferias legitima la idea de que cualquier solución se sale de las manos y de las capacidades locales, requiriendo intervenciones "de emergencia" desde el Estado central. Sobre todo, se impone la idea que para articular estas regiones al desarrollo y a la economía modernas se requieren medidas extraordinarias (léase grandes inversiones de capital) que solo pueden ser garantizadas desde el centro, con el concurso de la empresa privada.

Así, aunque las periferias aparecen como desarticuladas y como producto del "abandono del Estado" de hecho se han constituido a partir de un régimen consistente de intervención, que se estructura a partir de diversas operaciones "técnicas" y de "instrumentos de planificación" que terminan por objetivar las condiciones de periferia. Sus formas de orden han implicado históricamente la creación un conjunto particular de de conceptos (como los de "frontera agrícola" o "aislamiento estructural"); de instituciones (como las Secretarías de Fronteras o las Oficinas de fomento a la colonización); de regímenes normativos (como los contratos de colonización, las leyes de baldíos o de tierras fiscales, el régimen de reservas privadas) y de tipos de territorio (territorios nacionales, zonas extremas, localidades aisladas, territorios de integración tardía).

Estos instrumentos técnicos sustentan una serie de líneas de acción alrededor de tres grandes ejes (Serje, 2013): primero, la penetración (hoy conocida como "conectividad") mediante la cual se ha buscado la inversión privada del superávit de mano de obra y de capital en la construcción de grandes obras de infraestructura física. Su objetivo es "integrar" estos territorios mediante sistemas de transporte que fundamentalmente articulan las zonas de explotación extractiva con las rutas del comercio global, ignorando las dinámicas internas e intrarregionales. Como ejemplo se puede citar el macro proyecto IIRSA que busca "integrar" comercialmente el continente suramericano.

Segundo, la explotación extractiva (maderera, minera, petrolera, agroindustrial), de los recursos tanto humanos como biogeográficos, que ha venido resultando en la racialización, la subordinación y, en muchos casos, en el genocidio de sus habitantes, así como en la erradicación de los bosques, el agotamiento de muchos ecosistemas y en la extinción de numerosas especies. Ha sido el resultado de la puesta en marcha de una "política del enclave" (Serje, 2005), mediante el establecimiento de regímenes extractivos, basados en contratos y concesiones de tierras y de 
recursos que han venido dando lugar a una nueva forma de latifundismo -ya no en manos del terrateniente paternalista, sino en las de herméticas figuras corporativas.

Y esta tendencia configura la tercera línea de acción: la delegación de las funciones del Estado en manos privadas. Más allá de la privatización de la inversión social como la salud o la educación, los Estados han venido delegando en estas regiones fronterizas funciones clave de gobierno como la seguridad, la planeación regional, o las regulaciones comerciales en cabeza de empresas privadas, gremios, asociaciones de empresarios o de ONG. Así a lo largo de su historia, se puede constatar la delegación de la presencia del Estado en manos de misiones, que montaron en muchos casos verdaderas economías de escala regional (como el caso de las misiones Jesuitas o Capuchinas en el siglo XVII, o de las misiones protestantes en el siglo XX); o de empresas comerciales como en el caso, tristemente célebre, del caucho en el Amazonas (como las Casas Arana y de Funes, que para explotar el caucho montaron un sistema masivo de esclavización y exterminio de los pueblos indígenas a comienzos del siglo XX). Hoy se privatiza abiertamente el manejo territorial mediante la cesión de grandes áreas para la minería, la explotación de recursos renovables como el agua y los bosques, para conservación y turismo ecológico, subordinado a sus pobladores a los intereses y prioridades de grupos corporativos.

Por último, es interesante notar que el estado de emergencia se perpetúa tras nociones como el "abandono" o la "ausencia del Estado", a pesar de que históricamente ha habido en estas zonas una presencia consistente de los Estados mediante este régimen de intervención que, irónicamente, se parece mucho al que hoy se conoce como Estado neoliberal, cuyas funciones se orientan a atraer y garantizar condiciones favorables a la inversión de los superávits de capital en los "centros", al tiempo en que se privatizan y se "tercerizan" sus funciones de regulación y de protección social.

\section{Excepcionalidad}

Sin duda, uno de los tropos comunes con los que se representan y se piensan las periferias y las fronteras internas es el de las "tierras de nadie": invariablemente aparecen como espacios liminales, por fuera del control del Estado, y de la civilización, donde se pueden romper las normas para imponer "la ley del más fuerte". En la medida en que estos lugares se piensan como espacios donde el orden vigente queda en suspenso y se levantan las normas cotidianas, allí rige, de facto, un estado de excepcionalidad.

Hannah Arendt, Walter Benjamin y Giorgio Agamben, entre otros, han señalado que la característica particular del poder soberano radica, más que en su capacidad de definir lo legal y de establecer un orden, en el hecho de que tiene también la prerrogativa de establecer momentos y espacios donde puede suspender su propio orden y legalidad para ejercer su poder arbitrariamente, a discreción y con impunidad.

En su trabajo sobre los campos de concentración, Giorgio Agamben (1997), propone que estos espacios "que se abren cuando el estado de excepción comienza a volverse la regla" (p.106), lejos de ser una anomalía del pasado, constituyen la "matriz oculta" y el nomos del espacio político en el que vivimos, pues "nos encontramos frente a un campo cada vez que se crea una estructura de esta naturaleza, independientemente de los tipos de crímenes que allí se cometan y de cualquiera que sea su denominación topográfica [pues] en todos estos casos, se trata de un espacio 
aparentemente inocuo que [...] de hecho delimita un área donde el orden se ve suspendido de facto y donde el que se cometan o no atrocidades depende, no de la ley, sino de la deferencia y del sentido ético de [quien] actúa temporalmente como [poder] soberano" (p. 113).

Y éste es precisamente el proceso que se produce en estas "ultimas fronteras" del capitalismo: recubiertas por el poderoso imaginario del "desierto", los paisajes y lugares no integrados formalmente al orden moderno aparecen como "áreas donde el orden se ve suspendido de facto": como tierras de nadie dispuestas para ser tomadas. Se crea así una condición de excepcionalidad que las sitúa "entre el afuera y el adentro, entre la excepción y la norma, entre lo lícito y lo ilícito, donde los conceptos mismos de sujeto, de derecho, de protección jurídica, pierden todo su sentido" (Agamben, 1997:110). No solo se naturaliza de este modo el poder que despoja su habitantes históricos de sus derechos consuetudinarios, se naturalizan simultáneamente las formas más salvajes de enriquecimiento donde todo vale (en últimas, el objetivo de su apropiación) que constituyen la condición de posibilidad de la puesta en marcha de la forma más básica de "acumulación por desposesión" (Harvey, 2004): la de la apropiación de las tierras, los paisajes y los saberes de los grupos que obstinadamente mantienen formas de vida social basadas en principios distintos a los del capitalismo. Las cifras crecientes de acaparamiento de tierras así lo atestiguan (ver Sassen, 2015; Oxfam, 2016, FAO, 2013). Se da así continuidad al proceso de "acumulación primitiva" (Marx, 1992) iniciado en el siglo XVI con la apropiación y desalojo de los comunes, que al tiempo con Europa se implementó en las Américas, África y Asia y continua hasta la actualidad.

\section{Reflexiones finales}

La característica fractal del centro-periferia como estructura organizativa de la producción del capital ha venido creando una nueva "geografía de la centralidad", como lo señala Saskia Sassen (2014). De esta forma, más que como una oposición estática entre centros y periferias"1, habría que pensar en la organización espacio-temporal del capital como una red fluida de polos nodales jerarquizados que se superpone de maneras inesperadas con una serie de zonas "periféricas"12 de las que éstos dependen para reproducir riqueza, invirtiendo de esta manera el postulado central de la teoría de la dependencia, que supone que son las economías de las periferia las que dependen del centro.

Muchos de estos márgenes y periferias, de estas "últimas fronteras" configuran hoy lo que Saskia Sassen (2014) denomina "zonas extremas" donde lenta y brutalmente se ha venido consumando la expulsión de sus habitantes históricos, para dar lugar a un proceso sin precedentes de concentración de tierras y de transformación de los ecosistemas y degradación ambiental. El devenir de estas regiones y sus habitantes se define de manera cada vez más directa desde los centros financieros desde donde se las ve como realidades abstractas, en términos de commodities, ignorando el sentido que tienen no solo para la vida de quienes allí habitan sino del planeta y de la humanidad en general.

Y las "semiperiferias", que introduce la teoría del sistema mundial moderno.

Esta coincide con la consolidación de una nueva geografía global que articula regiones económico-militares dando un papel secundario y subordinado a la organización basada en los límites naciones europeos y sus territorios coloniales (ver Mezzadra y Neilson, 2013) 
La apropiación de las fronteras internas y periferias ha sido, sin duda, uno de los capítulos centrales de la historia del capitalismo. Su anexión a los circuitos del capital ha estado marcada por historias de desplazamiento y por diversas formas de esclavitud, acompañadas de la destrucción de los paisajes de bosques y selvas y de la transformación profunda de muchos ecosistemas por medio de la extracción (de maderas, de riquezas mineras, etc.) o de la industrialización agropecuaria. En América Latina se ha tenido una visión positiva de este proceso, que ha sido celebrado como un paso no solo necesario sino benéfico, en la medida que se ha concebido ( $y$ en el sentido común se sigue concibiendo) como un proceso de avance en las etapas del progreso: el acenso de lo salvaje a lo civilizado y la superación del atraso y el subdesarrollo. Es hora de que comencemos a pensarlo en términos de la historia del capital, como un proceso global que está permanentemente reconfigurando la región, más allá de los espacios nacionales.

\section{Referencias bibliográficas}

AMIN, S. Le developpement inegal. Essai sur les formartions sociales du capitalisme peropherique. Paris: Éditions de Minuit, 1973.

AGAMBEN, G. The camp as nomos of the modern. In: DE VRIES, H. \& WEBER S. (editors). Violence, identity and self determination. Palo Alto: Stanford University Press, 1997, p. 106-118

ANDERSON, B. Imagined Communities: Reflections on the Orign and spread of nationalism. London: Verso, 1991.

ANIEVAS, A. \& NISANCIOGLU, K. How the West came to rule. The geopolitical origins of capitalism. London: Pluto Press, 2015.

BALES, K. Disposable people: New slavery in the global economy. Berkeley: University of California Press, 1999.

BANDIERI, S. Historia de la Patagonia. Buenos Aires: Penguin Random House Argentina, 2014.

BECKERT, S. El imperio del algodón: Una historia global. Barcelona: Editorial Crítica, 2016.

CARDOSO, F. y FALETO, E. Dependencia y desarrollo en América Latina. México D.F.: Siglo XXI, 1969.

CASO-BARRERA, L. Caminos en la selva: Migración, comercio y resistencia. Mayas, yucatecos e Iztaes, siglos XVII-XIX. México D.F.: El Colegio de México-FCE, 2002.

CHATERJEE, P. The nation and its fragments. Colonial and Post colonial histories. Princeton: Princeton University Press, 1994.

DAS, V. \& POOLE, D. Anthropology in the margins of the state. Santa Fe: School for American Research Press, 2004. 
DELEUZE, G. \& GUATTARI, F. Capitalisme et schizophrénie: Mille plateaux. Paris: Editions de Minuit, 1980.

DRAYTON, R. The collaboration of Labour: Slaves, Empires and Globalizations in the Atlantic World, c1600-1850. In: HOPKINS, A.G. (editor). Globalization in World History. New York: Norton, 2002, p. 98-114

DOS SANTOS, T. Dependencia y cambio social. Santiago de Chile: Universidad de Chile, 1972

ESTEVA, G. Development. In: SACHS, W. (editor). The developement dictionary: A guide to knowledge as power. London: Zed Books, 1992, p. 6-25.

FRANK, A.G. World Accumulation 1942-1789. London: Macmillan, 1978.

FAO (FOOD AND AGRICULTURE ORGANIZATION OF THE UNITED NATIONS). Dinámicas del Mercado de tierras en América Latina y el Caribe. 2003. Disponible en Internet: http://www.rlc.fao.org/ fileadmin/content/events/semtierras/acaparamiento.pdf

FERMÉ, M. The violence of numbers: Consensus, competition, and the negotiation of disputes in Sierra Leone. Cahiers d'études africaines, 1998, Vol. 38, № 150-152, p. 555-580.

GARCIA JORDAN, P. Cruz y Arado, Fusiles y Discursos: La construcción de los orientes en el Perú y Bolivia. Lima: IFEA-IEP, 2002.

GASCHÉ, J. y ECHEVERRI, J.A. Hacia una sociología de las sociedades bosquesinas. En: OCHOA, D. y GUIO C. (compiladores). Control social y coordinación: Un camino hacia la sostenibilidad amazónica. Bogotá: Universidad Nacional de Colombia - Defensoría del Pueblo - Corpoamazonia, Parques Nacionales, 2004, p. 165-181.

GLEICK, J. Chaos: Making of a new science. New York Penguin Books, 2008 [1987].

HARVEY, D. The new imperialism: Accumulation by dispossession. Socialist Register, 2004, № 40, p. 63-87.

HARVEY, D. Spaces of global capitalism. A theory of uneven geographical development. London: Verso, 2006.

LEFEBVRE, H. La production de l'espace. Paris: Anthropos, 1994 [1974].

LEVI-STRAUSS, C. Les discontinuités culturelles et le développement économique et social. En : Anthropologie Structurale Deux. Paris: Plon, 1973 [1955] p. 365-376.

LOPEZ, S. Representaciones de la Patagonia: Colonos científicos y políticos, 1870-1914. La Plata: Ediciones Al Margen, 2003.

LUXEMBURG, R. The Accumulation of capital. New York: Routledge, 2003 [1913]. 
MARX, C. Capital, Volume 1: A critique of political economy. London: Penguin Classics, 1992 [1867].

MEZZADRA, S. \& NEILSON B. Border as method, or, the multiplication of labor. Durham NC: Duke University Press, 2013.

MONTEJANO, D. Anglos y Mexicanos en la formación de Texas, 1836-1986. México D.F.: CNCA-Alianza Editorial, 1987.

MUDIMBE, V. The invention of Africa. Gnosis, Philosophy and the order of knowledge. Bloomington: Indiana University Press, 1988.

NAVARRO FLORIA, P. Historia de la Patagonia. Buenos Aires: Centro de estudios políticos y admnistrativos, 1999.

NUÑEZ, A.; SANCHEZ, R. y ARENAS, F. (editores). Fronteras en Movimiento e imaginarios geográficos. La cordillera de los Andes como espacialidad sociocultural. Santiago de Chile: Serie GEOlibros, Instituto de Geografía, Pontificia Universidad Católica de Chile-RIL Editores, 2013.

ORTELLI, S. Del despoblamiento a la Aridez. El septentrión novo-hispano y la idea de desierto en la época colonial. En: TREJO-BARAJAS, D. (compilador). Los desiertos en la Historia de América. Una mirada multidisciplinaria. Morelia: Universidad Michoacana de San Nicolás de Hidalgo-Universidad Autónoma de Coahuila, 2011, p. 17-44.

OXFAM. An economy for the 1\%. Oxfam Briefing Paper, 2016, № 210. Disponible en Internet: https://www.oxfam.org/sites/www.oxfam.org/files/file_attachments/bp210-economy-one-percenttax-havens-180116-en_0.pdf

PÉREZ-TAYLOR, R.; OLMOS AGUILERA, M. y SALAS QUINTANAL, H. (editores). Antropología del desierto. México D.F.: UNAM- El Colegio de la Frontera Norte, 2007.

RAJCHENBERG, E. y HEAU-LAMBERT, C. El septentrión mexicano: entre el destino manifiesto y el imaginario territorial. Journal of Iberian and Latin American Studies, 2005, Vol. 11, № 1, p. 31.

RAJCHENBERG, E. y HEAU-LAMBERT, C. La frontera en la comunidad imaginada del siglo XX. El Colegio de la Frontera Norte, 2007, Vol. 19, №39, p. 37-61.

RAMA, A. La ciudad letrada. Hannover NH: Ediciones del Norte, 1984.

SAID, E. Orientalism. London: Vintage Books, 1979.

SAMADDAR, R. The Marginal Nation. Transborder migration from Bangladesh to West Bengal. London: Sage, 1999.

SANTOS, M. L'espace partagé. París: Libraires Techniques, 1975.

SANTOS GUERRERO, F. y BARCLAY, F. Órdenes y desordenes en la selva central: Historia y economía de un espacio central. Lima: IFEA-IEP, 1995. 
SASSEN, S. Expulsions: Brutality and complexity in the global economy. London: Belknap Press, 2014.

SERJE, M. El revés de la nación. Territorios salvajes, fronteras y tierras de nadie. Bogotá: Ediciones Universidad de los Andes, 2005.

SERJE, M. El mito de la ausencia del Estado: La incorporación económica de las 'zonas de frontera' en Colombia. Cahiers des Amériques Latines, 2013, № 71, p. 95-116.

SUBIRATS, E. El continente vacío: La conquista del Nuevo Mundo y la conciencia moderna. México: Siglo XXI, 1994.

SUBIRATS, E. Writing and cities. In: LEJEUNE, J.F. (editor). Cruelty \& Utopia: Cities and landscapes of Latin America. New York: Princeton Architectural Press, 2005, p. 84-97.

TREJO-BARAJAS, D. (compilador). Los desiertos en la Historia de América. Una mirada multidisciplinaria. Morelia: Universidad Michoacana de San Nicolás de Hidalgo-Universidad Autónoma de Coahuila, 2011.

TROUILLOT, M-R. Peasants and capital. Dominica in the world economy. Baltimore: Johns Hopkins University Press, 1988.

WINICHAKUL, T. Siam mapped: A history of the geo-body of a nation. Honolulu: University of Hawaii Press, 1997. 